\section{A simple sampler for subglacial water bodies}

Subglacial waters and water bodies have received increased attention as factors in ice dynamics (Clarke, 2005), as sites of organic carbon processing under continental ice sheets during glacial intervals (Zeng, 2003; Skidmore and others, 2005), and as microbial habitats analogous to environments on Mars and some icy satellites in the outer solar system (Gaidos and others, 2004). We have designed, constructed and tested a novel device to retrieve subglacial water samples. The sampler is designed to operate in the narrow boreholes made by thermal or conventional drilling, and to retrieve a watertight and gas-tight sample from a specified water depth above the bottom of the hole or glacier bed. The device operates without electrical power, sensors, or communication with the surface, and is ideal for environments where robust but low-complexity solutions to sampling are required.

Figure 1 shows a schematic representation of the sampler, along with a picture taken immediately before its deployment into a borehole. Our device consists of: a sample chamber (A) open at both ends; a closure mechanism comprising two conical end-plugs (B) connected by a pulley-and-cable system (C) and driven by two coil springs (D); a triggering mechanism consisting of a spring-loaded ratchet $(\mathrm{E})$ held closed by tension on a line (F) below which is suspended a weight $(\mathrm{G})$; and a load-bearing frame $(\mathrm{H})$ which runs from the attachment point to the deployment cable to the triggering device beneath the sample bottle. Water flows freely through the chamber during descent to the sampling depth. The chamber is sealed when the weight touches the bottom and tension on the line is removed. Thus the sampling depth relative to the bottom is set by the length of the line to the weight, which can be varied. The chamber remains closed when tension is reapplied during retrieval. The sampler has a maximum diameter of $4 \mathrm{~cm}$ and the length (without the line and weight) is $185 \mathrm{~cm}$.

The $400 \mathrm{~mL}$ sample chamber is fabricated from polyvinylidene fluoride (PVDF) and is resistant to many chemical treatments, including $5.25 \% \mathrm{NaOH}$ (bleach) which we use for sterilization and DNA decontamination. A sampling port $(\mathrm{I})$ and inlet $(\mathrm{J})$ in the wall of the sampler are plugged by 1/4-20 screws. After sample retrieval, the plugs are removed and replaced by valved HPLC fittings through which the sample is extracted. The conical end-plugs are also constructed of PVDF and fitted with rubber O-rings. The plugs are closed by stainless-steel coil springs, the bottom one via a plastic driver $(K)$ that is in turn connected to the triggering mechanism through a brass actuator bar $(\mathrm{L})$. One side of the spring is stopped by a plastic spacer $(M)$, the length of which can be adjusted to achieve the desired closure force. The trigger assembly consists of a brass ratchet (E) that rocks about a fixed pin and hooks onto the actuator bar. The sampler is open when the actuator bar is held by the ratchet. The force of a coil spring $(\mathrm{N})$ to move the ratchet open and release the actuator bar is opposed by the tension on the line $(F)$ to the weight $(G)$. Removal of the tension releases the actuator and closes the chamber. The weight is a $4.5 \mathrm{~kg}$ cast-iron bar wrapped in waterproof tape. A $60 \mathrm{~cm}$ shock cord $(\mathrm{O})$ is included in the line to eliminate spurious triggering of the closure mechanism during deployment. The external frame $(\mathrm{H})$ consists of four C203 stainless-steel bands of $0.6 \mathrm{~mm}$ thickness, to which the sampler components are fastened.
The device is deployed at the end of the hot-water hose used for drilling. Connection is provided by a 0.25 in $(\sim 0.63 \mathrm{~cm})$ male BSP fitting at the top of the frame. The sampler is suspended above the borehole on a winch and the weight is deployed into the hole to achieve tension on the trigger line. A cocking key $(\mathrm{P})$ is inserted into the springloaded lower end-plug driver piece to move it into the open position until the actuator bar is latched into the ratchet. The sampler is then deployed into the hole with minimum disturbance. In June 2006 we tested this device on the Vatnajökull ice cap, Iceland, and successfully retrieved a water sample from the subglacial lake in the western Skaftárkatlar volcanic region. The ice thickness at this location is $300 \mathrm{~m}$ and the lake depth is another $115 \mathrm{~m}$ (as determined by a pressure sensor-equipped cable). The hydrology, geochemistry and biology of the lake as inferred from this sample and additional measurements will be discussed elsewhere (Gaidos and others, unpublished information). The sample was anoxic, sulfidic and gascharged: degassing (presumed to be $\mathrm{CO}_{2}$ ) was observed upon retrieval of the sample, and a strong sulfide smell remained in the closed sampler for 48 hours after sample
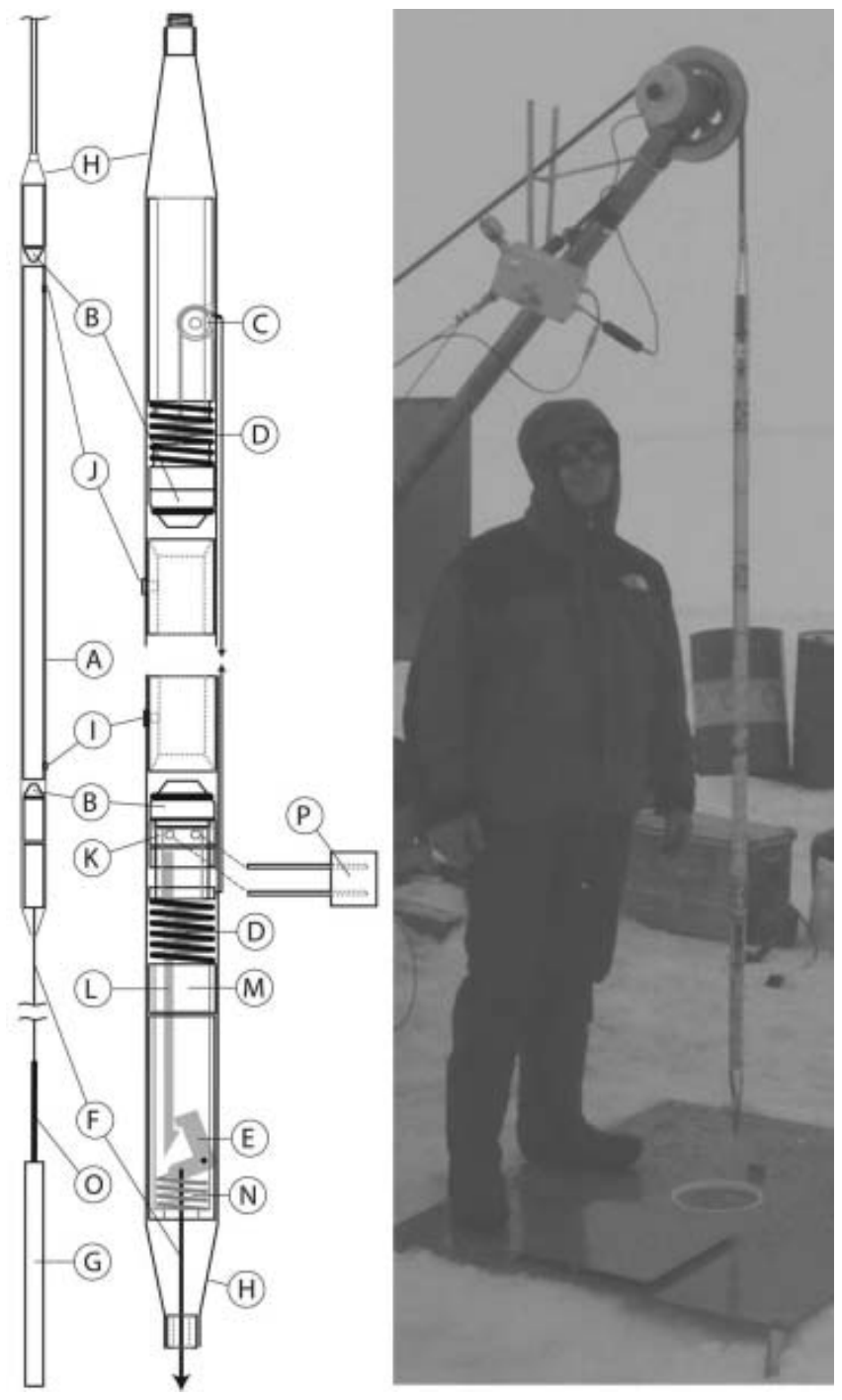

Fig. 1. Schematic representation of the subglacial water sampler (see text for details, labelled A-P), and photograph taken immediately before deployment in the borehole. 
retrieval and processing. These observations confirm that the sampler remained gas-tight during retrieval.

A limitation of this design was its tendency to snag in the borehole during retrieval. We think this problem was due to a combination of: (1) the length of the chamber (driven by the sample volume requirements); (2) the length and stiffness of the weight; and (3) protruding connections in the sampler chain. We recommend the following modifications to the original sampler design: replacement of the stiff weight with a longer, flexible hose filled with lead shot; streamlining or removal of cable connectors; and the use of flush, flathead screws on all exterior locations.

Several borehole bailers are available commercially; however, these are usually based on the principle of hydraulic closure during ascent (e.g. by ball valves). These suffer from loss of gas or sample, lack of containment, and inability to specify sampling depth. A programmable, pressure-triggered sampler offers precise control of sampling but is costlier and requires a priori knowledge of depths, as well as electronics housing and interface equipment. Our design is an intermediate solution in terms of cost and complexity.

\section{ACKNOWLEDGEMENT}

This material is based upon work supported by the National Aeronautics and Space Administration through the NASA Astrobiology Institute under Cooperative Agreement No. NNA04CC08A issued through the Office of Space Science.
School of Ocean and Earth

Science and Technology,

University of Hawaii at Manoa,

Honolulu, Hawaii 96822,

USA

E-mail: gaidos@hawaii.edu

Orkustofnum (National Energy Authority),

Grensásvegi 9,

IS-108 Reykjavík,

Iceland
Institute of Earth Sciences,

Andri STEFÁNSSON

University of Iceland,

Luiz GABRIEL

Sturlugata 7,

IS-101 Reykjavík,

Iceland

Icelandic Meteorological Office, Tomas JOHANNESSON Bústaðavergur 9,

IS-150 Reykjavík

Iceland

Department of Earth Sciences,

Montana State University,

Bozeman, Montana 59715,

USA

Department of Environmental Sciences, Brian LANOIL

University of California

Riverside, California 92521,

USA

30 December 2006

\section{REFERENCES}

Brian GLAZER

David HARRIS

Zensho HESHIKI

Nina JEPPSSON

Mary MILLER

Thorsteinn THORSTEINSSON

Bergur EINARSSON

Vilhjálmur KJARTANSSON

Clarke, G.K.C. 2005. Subglacial processes. Annu. Rev. Earth Planet. Sci., 33, 247-276.

Gaidos, E., B. Lanoil, T. Thorsteinsson, A. Graham and M. Skidmore. 2004. A viable microbial community in a subglacial volcanic crater lake, Iceland. Astrobiology, 4(3), 327-344.

Skidmore, M., S.P. Anderson, M. Sharp, J. Foght and B.D. Lanoil. 2005. Comparison of microbial community compositions of two subglacial environments reveals a possible role for microbes in chemical weathering processes. Appl. Environ. Microb., 71(11), 6986-6997.

Zeng, N. 2003. Glacial-interglacial atmospheric $\mathrm{CO}_{2}$ change - the glacial burial hypothesis. Adv. Atmos. Sci., 20(5), 677-693. 